\title{
Research on Classroom Action of College English Writing Teaching based on Hybrid Learning
}

\author{
Jingjing Guan ${ }^{1, a}$ \\ ${ }^{1}$ Qiqihar Medical University, Qiqihar, Heilongjiang, 161006 \\ a email: 33094995@qq.com
}

Keywords: Classroom Action, College English Writing, Hybrid Learning

\begin{abstract}
In recent years, the self-reflection teaching mode has become more and more valued by educators, and the action research developed under this model advocates teachers to systematically observe and reflect on their own teaching actions, discover and ask questions. To achieve the purpose of improving teaching methods and improving teaching results. At the same time, the teacher himself established a new teaching concept in the research process, constantly improving the teaching professional skills. Action research effectively solves the problem of disconnection between teaching and research, and is a new type of teaching philosophy and method.
\end{abstract}

\section{Introduction}

Action Research is a teaching theory research method developed on the basis of self-reflective teaching mode. It is an exploratory activity carried out by teaching practitioners to improve teaching methods and improve teaching effects. It originated in the West in the 1930s. In the 1970s and 1980s, this theory and its corresponding practice developed rapidly. At this time, the research on the purpose, object, steps and characteristics of action research reached a climax. From the discussion of many researchers, it can be found that action research is a cyclical process, which consists of planning, action, observation, analysis and reflection, including the following steps: teachers through the experience of teaching practice and Thinking, realizing the problems in teaching; proposing targeted solutions; specifying and implementing teaching plans to solve the problems; evaluating the results of teaching actions; re-determining teaching problems based on analysis and evaluation for the next round the study.

\section{English Teacher Action Research}

The basic point of action research is the combination of "action" and "research". This feature makes action research an effective way to solve the problem of disconnection between theory and practice. It also allows teachers to serve as "teacher researchers". Teach and learn, apply what you have learned. But is this convenient teacher's research method "is it really research?" Many scholars have questioned the scientific issues of action research. Woodward thinks that she is different from other natural and social sciences and different from traditional education. Action research has characteristics of general qualitative research such as fun, creativity, efficiency, and practicality. Although there are certain deficiencies, it does not affect teachers to use their own controllable resources to carry out some small teaching action research.

In the process of conducting action research, teachers constantly reflect on their teaching behaviors by recording teaching diaries and participating in group discussions, improve and improve their work, and improve their rational understanding of the syllabus, teaching process and learning process. The result is continuous teaching. Improvement and the development of motivation and ability for teacher development. Therefore, teaching action research is also a feasible research topic for the reform of teacher training mode. Internationally, in the field of second language/foreign language education, efforts to improve the professionalism of teachers have gone through the development stage from "Teacher Training” to "Teacher Education". The teacher 
training focuses on teaching the relevant knowledge of foreign language teaching, practicing classroom teaching methods and skills, and the objectives are clear and specific. The teacher training focuses more on how to train teachers to form and develop their own teaching theories, and clearly make in teaching. The nature of each decision, the research and teaching, the formation of self-awareness and self-assessment strategies with a clear vision, the ultimate goal is to improve the professional quality and overall quality of teachers, that is, to focus on teacher development (Teacher Development). This recently used concept emphasizes that on the basis of "education", teachers are encouraged to reflect on their own teaching, observe their own classroom behavior, evaluate their own teaching effects, and carry out "Research in Teaching Behavior" (Action Research). Said, teach teachers how to verify others' findings in teaching practice, form their own beliefs, reflect on themselves, make every decision have a basis, and each judgment has theoretical support.

The action research model is usually a "loop" process that involves several steps. There are seven steps in more detailed, mainly including: discovery of a problem, collecting relevant data, proposing a solution, design practice plan, a monitoring result, a improvement plan, and also from her sponsor Lewin The four-step form of development and evolution, that is, the discovery of the problem, the solution of the first solution, the implementation of the results of the evaluation, and other scholars simply simplifies this step into the problem of raising a hypothesis. The author summarizes the action research process of the above researchers, and follows the following steps in the practice of English teaching: discovering problems, analyzing problems, making hypotheses, solving problems, and evaluating results.

\section{The application of action research in college English writing teaching}

In the English writing teaching, the author summarizes some problems in the students' English writing through the review of the students' English writings. At the chapter level: the structure of the article does not conform to English habits, and the chapter coherence is poor; the content of the article is thin and the paragraphs are not fully expanded. At the sentence level: the sentences are poorly connected, a large number of short sentences are full of the full text, and the sentence expression is severely finished. At the lexical level: the words are not rich, and you cannot use new words learned by the university. On the level of basic language knowledge: there are many simple mistakes, such as spelling, fixed phrase collocation, etc. The same mistakes will occur many times and repeatedly. On the level of feedback to teachers: do not pay attention to teacher comments.

In response to the above problems, the author first conducts a reflection survey from the perspective of the teacher, and analyzes the cause of the problem: the teaching method used by teachers nowadays is: Is the method of "reading, explaining, student writing, teacher reviewing" appropriate? Does the teacher's regular method of reviewing the composition work in the feedback? After the teacher's reflection on himself, the student's survey is conducted through questionnaires and interviews to understand the students' understanding of English writing and the knowledge of English writing knowledge. In the development of the English writing process, their recognition of the current teaching methods of teacher writing, and the response of students to teacher feedback. The survey results show that most students are not interested in English writing. They are only doing English writing exercises to complete the writing tasks assigned by the teacher. Therefore, after writing, they will not take the time to carefully check for errors such as spelling and grammar. Secondly, in writing, they do not consider the use of words to make sentences, and they do not deliberately use English writing skills. They believe that theory and practice cannot be combined in actual writing. In this way, the knowledge taught by the teacher in the classroom is in a state of disconnection from the actual writing. Students often write with a pen and turn English writing into a simple translation process. Therefore, the structure of the article written does not conform to English habits. At this point, the current writing method of "reading, explaining, student writing, teacher reviewing" cannot meet the writing needs of students. Teachers expect that the writing knowledge that students receive in reading cannot be reflected in actual writing. Third, they feel that the process of writing is a process of Chinese-English translation. Their writing is the process 
of translating Chinese sentences in the mind into English. Fourth, they believe that their own language skills are also the reason that hinders their successful writing. For example, the vocabulary is small and the grammar knowledge is weak, which causes the text to be filled with a large number of short sentences, and the expression is severely finished. Fifth, they never pay much attention to the teacher's comments, because they will make the same mistakes later. Judging from the survey results, the two problems that teachers think in their reflection on themselves are indeed the factors that cause students' writing problems. The survey results also provide teachers with additional information. In writing teaching, how should teachers inspire students' writing interests and what kind of writing teaching methods should be used to guide students to write correct English writings.

After finding out the above reasons, according to the steps of the action research, draw up the hypothesis of solving the problem: using the textual model based on the rhetorical writing in college English writing. There are special reasons for choosing a teaching method that contrasts rhetoric writing. In contrast to rhetorical theory, in the process of foreign language learning, the organization of texts reflects the particularity of language and culture. The language of the mother tongue and the tradition of rhetoric can interfere with the writing of the first language. In the composition of the text, the difference between English and Chinese is that the development of English text tends to be deductive, while Chinese tends to be generalized. Kaplan, Ullar Conner showed that the passages of the Eastern language containing Chinese, Japanese, Thai, and Korean are spiral, and the subject is often developed in an indirect way. English passages often begin with topical sentences, and the organization and development of texts are linear. They believe that in terms of form, there is a dominant expression between English sentences and between paragraphs, that is, the way of cohesion and coherence is promoted by the use of vocabulary. However, Chinese emphasizes the implicit meaning, that is, the expression "only can be said to be unspeakable." Languages have commonalities, but more are different. However, students who are able to give them the deepest memory when learning should be similar in English and Chinese. This is also why students have turned the process of writing into a process of smearing, without considering the similarities and differences in the structure of English and Chinese texts, so one of the reasons why English writing has a little Chinese taste.

In the revision stage, mainly students and teachers have evaluated and revised the article. The first is the self-assessment of students. In this session, teachers should guide students to judge their own articles. Students should be made aware of the various aspects of the essay, including the content of the article, the structure of the article, and the grammatical wording. If the structure of the article is complete? Is the organization clear? Is the content rich? Is the theme clear? In this way, on the one hand, it is convenient for students to grasp the standards of composition evaluation and the symbols of correcting composition; on the other hand, students' ability to find problems and solve problems has been effectively trained and improved. Second, the students evaluate each other. Students judge at the same level on the basis of self-evaluation, make detailed revisions to the students' articles, and write revised comments. This will easily create a positive atmosphere and help ease the writing to students. pressure. Third, the teacher corrects the teacher's article on the student's article from the content, structure to grammar and expression, and comprehensively corrects it, and writes critical comments, and comments on the students' self-evaluation and mutual evaluation. Affirm the advantages and point out the problem. During the period, the teacher selected several excellent works of the students as a model, presented the students, organized the students to seriously discuss and analyze the content of the articles, the structure of the texts, and the means of linking the texts, so that the students found problems in their compositions during the discussion, so that the article can be better corrected until the final draft.

\section{Conclusion}

In the course of action research, many new problems have also been encountered. Teachers hope that students can pay attention to grammar, spelling and other issues in the writing process of cooperative learning groups. Teachers do not want to see such problems in writing. However, in the actual process, based on the language ability of the students themselves, there is a phenomenon that 
the modification is not in place. Even this time there was a change, and there will be another crime again next time. That is to say, in the process of language acquisition, students have a hurdle that can't go through, that is, the phenomenon of "petrochemical" language. At the same time, in cooperative learning, teachers expect students to develop the ability to learn in cooperation, but there are also a few students who refuse to cooperate. Action research is a cyclical process. This study can lead to new research on the above issues, which are still to be paid attention to in future action research.

\section{Acknowledgements}

Source of the Question: 2018 "Multi-Learning Learning Research in the Context of Internet +" Project of the Education Management Information Center of the Ministry of Education

Title: Research on College English Writing Teaching Based on Blended Learning

Question number: EIJYB2017-143

\section{References}

[1] Yan Linlin. English undergraduate lexical competence survey [J]. Journal of PLA University of Foreign Languages, 2004(4): 35-38.

[2] Guo Xiaoying, Mao Hongmei. Experimental study on the influence of chunk teaching on English writing ability [J]. Shandong Foreign Language Teaching, 2010(3): 52-59.

[3] Tian Jinmei. The application of teacher action research in English writing teaching [J]. West China Science and Technology, 2009 (18): 87-89.

[4] Zhang Wei. Research on Vocabulary Teaching Action in College English Classroom [J]. Journal of Yulin Teachers College: Philosophy and Social Sciences, 2009(1): 147-150.

[5] Zhang Xin. The use of prefabricated chunks in the teaching of college English process writing [J]. Journal of Xiangfan Vocational and Technical College, 2010(1): 117-120. 